\title{
Are glucose levels, glucose variability and autonomic control influenced by inspiratory muscle exercise in patients with type 2 diabetes? Study protocol for a randomized controlled trial
}

\author{
ASO Schein ${ }^{1+}$, APS Correa ${ }^{1,2+}$, Karina Rabello Casali ${ }^{3}$ and Beatriz D. Schaan ${ }^{1,4,5^{*}}$
}

\begin{abstract}
Background: Physical exercise reduces glucose levels and glucose variability in patients with type 2 diabetes. Acute inspiratory muscle exercise has been shown to reduce these parameters in a small group of patients with type 2 diabetes, but these results have yet to be confirmed in a well-designed study. The aim of this study is to investigate the effect of acute inspiratory muscle exercise on glucose levels, glucose variability, and cardiovascular autonomic function in patients with type 2 diabetes.
\end{abstract}

Methods/design: This study will use a randomized clinical trial crossover design. A total of 14 subjects will be recruited and randomly allocated to two groups to perform acute inspiratory muscle loading at $2 \%$ of maximal inspiratory pressure (PImax, placebo load) or $60 \%$ of PImax (experimental load).

Discussion: Inspiratory muscle training could be a novel exercise modality to be used to decrease glucose levels and glucose variability.

Trial registration: ClinicalTrials.gov NCT02292810.

Keywords: breathing exercises, exercise, glucose, type 2 diabetes

\section{Background}

Hyperglycemia is the main cause of the clinical manifestations and acute and chronic complications of diabetes mellitus. Reducing glucose levels through nonpharmacological $[1,2]$ and pharmacological therapy is the cornerstone of type 2 diabetes management $[3,4]$. Goals for optimal diabetes management include reducing glycated hemoglobin (HbA1c) levels to $7 \%$ and implementing a number of cardiovascular risk reduction strategies $[5,6]$.

\footnotetext{
* Correspondence: beatrizschaan@gmail.com

${ }^{\dagger}$ Equal contributors

'Exercise Pathophysiology Research Laboratory, Hospital de Clínicas de Porto Alegre, Porto Alegre, Rio Grande do Sul, Brazil

${ }^{4}$ Graduate Program in Endocrinology, Universidade Federal do Rio Grande do Sul, Porto Alegre, Rio Grande do Sul, Brazil

Full list of author information is available at the end of the article
}

However, chronic complications of diabetes can develop even when these targets are met. This can be attributed to genetic and epigenetic factors [7], disruption of repair mechanisms [8], and, possibly, high glucose variability even when optimal HbA1c levels are achieved. Glucose variability is the fluctuation of glucose levels during the day, including episodes of hypoglycemia and hyperglycemia [9]. Measurement of glucose levels in intersticium throughout the day by continuous glucose monitoring systems $[10,11]$ or periodic capillary blood-glucose measurements [12, 13] have been used to evaluate glucose variability. Several conventional measures are available to quantify this parameter and have been widely reported in the literature over the past years $[14,15]$, including the mean amplitude of glycemic excursions [16], the standard deviation of glucose, and the mean of daily 
differences [17]. Non-conventional methods, which use mathematical and statistical analysis of the dynamic characteristics of glucose levels, as measured using continuous glucose monitoring systems, through spectral analysis and symbolic analyses, were recently reported [18].

Exercise training, consisting of aerobic exercise, resistance exercise, or a combination of both, is a useful tool for reducing HbA1c levels in type 2 diabetes $[2,19,20]$. It is also associated with several other benefits, including improved blood pressure control [21], reduction of skeletal muscle frailty [22], reduction of inflammation [23], and improved cardiovascular autonomic function [24]. Additionally, a recent study showed that an acute bout of aerobic or resistance exercise is associated with lower glucose variability [18], opening a new venue of benefits to explore.

Considering that many diabetic patients, especially those with autonomic neuropathy, have poor exercise tolerance or are completely unable to perform conventional exercises [25], alternatives should be sought. Inspiratory muscle training is a modality that has proven benefits in several clinical situations [26, 27], such as improving cardiopulmonary capacity and normalizing derangements in autonomic function [27, 28]. In patients with type 2 diabetes, this exercise modality can improve the strength and resistance of inspiratory muscles [29] and reduce glucose levels and glucose variability [30]. We speculate that, in type 2 diabetes, beyond reflecting the well-known improvement in insulin sensitivity induced by muscle contractions, inspiratory exercise would also yield improvements in cardiovascular autonomic function $[27,28]$. Thus, the aim of this study is to investigate the effect of acute inspiratory muscle exercise on glucose levels, glucose variability, and autonomic control in patients with type 2 diabetes.

\section{Methods/design Study design}

This study is a randomized clinical trial with a crossover design.

\section{Outcome measures}

The difference in glucose levels before and after exercise (evaluated by continuous glucose monitoring systems; glucose level after exercise minus glucose level before exercise) is the primary outcome measure. The secondary outcome measures are: (1) changes in glucose variability, which will also be evaluated by continuous glucose monitoring systems through conventional (mean amplitude of glucose excursion, variation of glucose, coefficient of variation of glucose, and standard deviation of glucose) and non-conventional indices (spectral analysis and symbolic patterns: no variation); (2) changes in cardiovascular autonomic control, which will be evaluated by blood pressure variability and heart rate variability (measures of power spectral density of low frequency, high frequency and very low frequency bands). Table 1 shows the measures that will be evaluated to achieve the desired results.

\section{Sample size and power calculation}

According to preliminary results obtained in our laboratory [31], the sample size was estimated in 14 individuals with type 2 diabetes, allowing for a dropout rate of $10 \%$. This sample size would detect a $34 \mathrm{mg} / \mathrm{dl}$ difference in glucose levels between the intervention inspiratory load of $60 \%$ and the placebo inspiratory load of $2 \%$, taking into account a standard deviation of $30 \mathrm{mg} / \mathrm{dl}$, a statistical power of $80 \%$, and a type I error rate of $5 \%$. WinPepi software was used to calculate the sample size.

\section{Inclusion and exclusion criteria}

The study will be conducted in patients with type 2 diabetes, diagnosed according to the National Diabetes Data Group criteria [5]. The inclusion criteria will be age 30 years and older, HbA1c between 7.5 and $10 \%$, and stable clinical condition, to ensure safe performance of the trial protocols. Patients will be recruited from the Outpatient Endocrinology Clinic of Hospital de Clínicas de Porto Alegre, Brazil. All study methods described are in accordance with the CONSORT Statement [32].

The exclusion criteria will consist of: insulin treatment, pregnancy, pulmonary disease (history of exerciseinduced asthma), cardiac arrhythmias, chronic kidney disease (glomerular filtration rate $<30 \mathrm{ml} / \mathrm{min}$ ), exclusive use of beta blockers as antihypertensive therapy, current smoking, varicose veins, and musculoskeletal conditions that would hinder safe completion of the proposed exercise protocols.

\section{Randomization}

The randomization sequence will be generated by computer. Randomization to the low-resistance inspiratory muscle exercise group ( $2 \%$ of maximal inspiratory pressure (PImax), placebo load) or the high-resistance inspiratory muscle exercise group (60\% of PImax, experimental load) will be performed by an investigator assigned exclusively to this task, who will not participate in the recruitment, assessment, or intervention phases of the study.

\section{Data collection}

Patients will be instructed to attend on three different days at the study laboratory for baseline evaluations, as follows: 
Table 1 Evaluated measures

\begin{tabular}{|c|c|c|c|}
\hline Time point & Data collection & Measure & Outcomes \\
\hline \multirow[t]{7}{*}{ Pre-evaluation } & Blood and urine analysis & $\begin{array}{l}\text { Glycemia, HbA1c, microalbuminuria } \\
\text { and creatinine }\end{array}$ & Metabolic responses \\
\hline & Cardiovascular autonomic assessment & Ewing tests & $\begin{array}{l}\text { Diagnosis of cardiovascular } \\
\text { autonomic neuropathy }\end{array}$ \\
\hline & $\begin{array}{l}\text { International Physical } \\
\text { Activity Questionnaire }\end{array}$ & Survey & Physical activity estimates \\
\hline & Inspiratory muscle test & $\begin{array}{l}\text { maximal inspiratory mouth } \\
\text { pressure (PImax) }\end{array}$ & Inspiratory muscle strength \\
\hline & Pulmonary function test & $\begin{array}{l}\text { maximum voluntary ventilation, } \\
\text { forced vital capacity, vital } \\
\text { capacity, forced expiratory } \\
\text { volume }(1 \mathrm{~s}) \text {, forced expiratory } \\
\text { volume }(1 \mathrm{~s}) / \text { vital capacity and } \\
\text { forced expiratory volume } \\
(1 \mathrm{~s}) / \text { forced vital capacity }\end{array}$ & Pulmonary flow and volume \\
\hline & Rest electrocardiogram & 12-lead electrocardiogram & Electrical activity of the heart \\
\hline & Cardiopulmonary exercise testing & 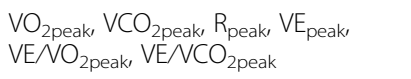 & Ventilatory and metabolic variables \\
\hline \multirow[t]{2}{*}{ At rest } & $\begin{array}{l}\text { Continuous glucose } \\
\text { monitoring system }\end{array}$ & Glucose concentration & Glucose levels and variability \\
\hline & Biopac system & $\begin{array}{l}\text { Continuous recording } \\
\text { of blood pressure }\end{array}$ & $\begin{array}{l}\text { Blood pressure and heart rate } \\
\text { variability in time and } \\
\text { frequency domains }\end{array}$ \\
\hline \multirow[t]{2}{*}{ Controlled ventilation } & $\begin{array}{l}\text { Continuous glucose } \\
\text { monitoring system }\end{array}$ & Glucose concentration & $\begin{array}{l}\text { Glucose concentration } \\
\text { and variability }\end{array}$ \\
\hline & Biopac system & $\begin{array}{l}\text { Continuous recording } \\
\text { of blood pressure }\end{array}$ & $\begin{array}{l}\text { Blood pressure and heart rate } \\
\text { variability in time and } \\
\text { frequency domains }\end{array}$ \\
\hline \multirow{2}{*}{$\begin{array}{l}\text { Inspiratory muscle exercise } \\
\text { ( } 2 \% \text { or } 60 \% \text { of maximal } \\
\text { inspiratory mouth } \\
\text { pressure, PImax) }\end{array}$} & $\begin{array}{l}\text { Continuous glucose } \\
\text { monitoring system }\end{array}$ & Glucose concentration & Glucose levels and variability \\
\hline & Biopac system & $\begin{array}{l}\text { Continuous recording } \\
\text { of blood pressure }\end{array}$ & $\begin{array}{l}\text { Blood pressure and heart rate } \\
\text { variability in time and } \\
\text { frequency domains }\end{array}$ \\
\hline \multirow[t]{2}{*}{ Recuperation } & $\begin{array}{l}\text { Continuous glucose } \\
\text { monitoring system }\end{array}$ & Glucose concentration & $\begin{array}{l}\text { Glucose concentration } \\
\text { and variability }\end{array}$ \\
\hline & Biopac system & $\begin{array}{l}\text { Continuous recording } \\
\text { of blood pressure }\end{array}$ & $\begin{array}{l}\text { Blood pressure and heart rate } \\
\text { variability in time and } \\
\text { frequency domains }\end{array}$ \\
\hline
\end{tabular}

$\mathrm{HbA1c}$, glycated hemoglobin; PImax, inspiratory mouth pressure; $\mathrm{R}$, respiratory exchange rate; $\mathrm{VCO}_{2}$ peak: carbon dioxide output; $\mathrm{VE}$, minute ventilation; $\mathrm{VO}{ }_{2 \text { peak, }}$ peak oxygen uptake; $\mathrm{VE} / \mathrm{VO}_{2}$ : ventilatory equivalent for oxygen; $\mathrm{VE} / \mathrm{VCO}_{2}$ : ventilatory equivalent for carbon dioxide

- Day 1: Urine collection and fasting blood draw for assessment of glucose, HbA1c, creatinine, and microalbuminuria; physical examination; Ewing tests for autonomic assessment; and completion of the International Physical Activity Questionnaire.

- Day 2: Resting 12-lead electrocardiogram, inspiratory muscle and pulmonary function tests.

- Day 3: Cardiopulmonary exercise testing.

\section{Autonomic neuropathy evaluation}

The presence of cardiovascular autonomic neuropathy will be evaluated using digital electrocardiography (VNS-Rhythm Neurosoft, Ivanovo, Russia) as previously described [33] and the five noninvasive cardiovascular tests proposed by Ewing [34], as standardized in our institution [35]. The heart rate, electrocardiographically monitored, will be evaluated after 5 min of resting and before and after deep breathing, the Valsalva maneuver, and standing. Three tests will be used to evaluate the heart rate response to (1) deep breathing, (2) lying-tostanding heart rate ratio, and (3) a Valsalva maneuver. Two tests of blood pressure control will be performed during (1) orthostatic hypotension and (2) sustained handgrip. Two or more abnormal test results will be deemed diagnostic of cardiovascular autonomic neuropathy. Heart rate variation will be assessed while patients are asked to breathe deeply at a rate of six breaths per minute while being monitored using three-lead 
electrocardiography. The maximum and minimum heart rate during each breathing cycle will be measured, and the mean difference over six cycles will be calculated. The heart rate ratio test will be performed after a period of rest in the supine position, and heart rate variability will be determined by calculating the maximal to minimal heart rate ratio: the ratio of the longest $R R$ interval, measured around the 30th beat after standing up, to the shortest RR interval, measured around the 15th beat after standing up. The Valsalva maneuver will consist of forced exhalation into a mouthpiece with a pressure of $40 \mathrm{mmHg}$ for $15 \mathrm{~s}$, and the ratio of the maximum RR interval after this maneuver to the minimum RR interval during the maneuver will be calculated. Orthostatic hypotension will be defined as a decrease of $30 \mathrm{mmHg}$ in systolic blood pressure when the individual voluntarily changes from the supine to the standing position. Measurements will be obtained at minutes 1 and 3 after standing up. Sustained muscle contraction will be measured by a handgrip dynamometer. The dynamometer will be first squeezed to maximum isometric contraction in the dominant hand. The highest of three measurements will be taken; then patients will be asked to hold at $30 \%$ maximum for $3 \mathrm{~min}$. A rise in diastolic blood pressure of $<10 \mathrm{mmHg}$ is considered an abnormal response.

\section{Inspiratory muscle testing}

Inspiratory muscle function testing will be performed using a pressure transducer (MVD-500 V.1.1 Microhard System; Globalmed, Porto Alegre, Brazil), connected to a system containing two one-way valves (DHD Inspiratory Muscle Trainer, Chicago, IL, USA) and equipped with a $2 \mathrm{~mm}$ diameter orifice to relieve facial muscle pressure. Patients will be instructed to remain seated, with elbows resting on the chair; a nasal clip will be used during all maneuvers. The PImax will be determined after patients take a deep breath at tidal volume, followed by slow exhalation to residual volume, and then quickly perform a maximal inspiration against the occluded circuit with a small air leak. The test will be repeated at least three times, with a $1 \mathrm{~min}$ interval between repetitions, to obtain six measurements with $<10 \%$ variation $[29,36,37]$. The values obtained from the PImax readings will be verified directly on the transducer. Predicted values will be corrected for age and sex.

\section{Pulmonary function}

Measurements of forced vital capacity, vital capacity, forced expiratory volume in $1 \mathrm{~s}$, and their ratios (forced expiratory volume $(1 \mathrm{~s}) /$ vital capacity and forced expiratory volume ( $1 \mathrm{~s}) /$ forced vital capacity) will be obtained using a computerized spirometer (Eric Jaeger $\mathrm{GmbH}$, Würzburg, Germany), as recommended by the American
Thoracic Society [38], and results will be expressed as a percentage of predicted parameter. For maximum voluntary ventilation, subjects will be instructed to breathe as deeply and quickly as possible for $15 \mathrm{~s}$; volume measurement will begin after the patient is able to achieve and maintain maximum effort [38].

\section{Cardiopulmonary exercise testing}

Maximal functional capacity will be assessed by means of an incremental exercise test to be performed on a treadmill (Inbramed 10200, Porto Alegre, Brazil), using a ramp protocol with a speed of $2-6 \mathrm{~km} / \mathrm{h}$ and increasing slope of 4-10\% to reach exhaustion in about $10 \mathrm{~min}$ [36]. A 12-lead electrocardiogram tracing will be obtained every 1 min (Nihon Khoden Corp., Tokyo, Japan), and blood pressure will be measured every 2 min with a standard cuff sphygmomanometer. During the test, gas exchange variables will be measured breath-by-breath with a previously validated system (Metalyzer3B, CPX System; Cortex, Leipzig, Germany). Ventilatory and metabolic variables will be analyzed throughout the test. Peak oxygen uptake $\left(\mathrm{VO}_{2 \text { peak }}\right)$ will be defined as the highest value reached during the test.

\section{Study intervention}

After baseline evaluations, all patients will be instructed to present to the laboratory, three times per week for 2 weeks, for completion of the intervention stage of the study protocol, as follows:

- Day 1: Placement of the continuous glucose monitoring system. Patients should arrive at 8:00 a.m. for device placement. Patients using beta blockers will be advised to discontinue their medication 24 hours before the next study visit.

- Day 2: Acute inspiratory muscle exercise protocol (2 \% or $60 \%$ of PImax). Patients should arrive at 10:00 a.m. and will be instructed to rest in the supine position for $10 \mathrm{~min}$ for collection of baseline glucose, continuous blood pressure, and heart rate measurements. Participants will then start controlled ventilation for $10 \mathrm{~min}$. A 40-minute interval will be allowed to elapse before the start of acute inspiratory muscle loading. Pursuant to random group allocation, participants will receive loading to $2 \%$ of PImax (low resistance, placebo load) for $10 \mathrm{~min}$ or to $60 \%$ of PImax (high resistance, experimental load) until task failure. At the end of the exercise protocol, a 10-min recovery record will be obtained. Glucose levels will also be measured by capillary sample before and after the protocol reported above. 
Arterial oxygen saturation $\left(\mathrm{SpO}_{2}\right)$ mean arterial pressure, end-tidal carbon dioxide, calf blood flow, and calf vascular conductance will be measured during all protocols.

- Day 3: Continuous glucose monitoring system removal. Patients will be instructed to return to the laboratory at noon for removal of the device.

One week following these interventions, all subjects will return to the study facility to repeat these procedures, but using another randomized load for inspiratory muscle exercises.

The experimental sessions will take place at the Hospital de Clínicas de Porto Alegre Exercise Pathophysiology Research Laboratory. All experiments will be performed in a temperature-controlled room and all subjects will be instructed to refrain from consuming caffeinated beverages and alcohol for at least 12 hours and from exercise for at least 24 hours prior to the evaluation. Continuous assessment of bloodglucose levels and blood pressure will be performed before, during, and after all protocols. Patients will be asked to follow their habitual diet and keep a detailed food intake record across the 3 days of continuous glucose monitoring system use.

\section{Glucose variability evaluation}

Subjects will be admitted to the laboratory at 8:00 a.m., 24 hours before the acute inspiratory muscle exercise session, for placement of the continuous glucose monitoring system sensor (Enlite Glucose Sensor, Medtronic MiniMed Inc., Northridge, CA, USA). Glucose data are obtained every $5 \mathrm{~min}$, providing a total of 288 readings per day.

Individuals will be instructed to perform at least four capillary blood-glucose measurements per day, before each meal, for calibration. The monitoring will be performed by the patients themselves, with a digital glucometer (Accu-Check Performa, Roche Diagnostics, Mannheim, Germany). Along with the glucometer, diaries will be delivered to patients, in which they should record the glucose values at each measurement and also details of all meals ingested during the period of continuous glucose monitoring.

Glucose variability will be evaluated using conventional and non-conventional analyses. Conventional analysis will be conducted using the statistical properties of the glycemic series classically used $[16,39,40]$ and nonconventional analysis of glucose variability will be conducted by application of two methods to the glucose series, based on spectral analysis and symbolic dynamics. Spectral analysis is a linear method that allows quantification of the oscillatory components from a time series by autoregressive models, and is widely applied to heart rate and arterial pressure series [41]. Symbolic dynamics relies on the calculation of Shannon entropy of the distribution of patterns lasting three measures and the classification of frequent deterministic patterns lasting three measures, and distributes deterministic patterns of the group into four variations [42].

\section{Cardiovascular autonomic control evaluation}

Cardiovascular autonomic control will be measured continually before the protocol (during a $10 \mathrm{~min}$ rest), during the controlled ventilation plus acute inspiratory muscle exercise protocol ( $2 \%$ or $60 \%$ of PImax), and throughout the recovery period, using a noninvasive blood pressure device (NIBP100D system; Biopac, Santa Barbara, CA, USA) with a general purpose amplifier module (DA100; Biopac), according to methodological guidelines provided by Sherwood et al. [43]. This system acquires the blood pressure wave at a sampling frequency of $1000 \mathrm{~Hz}$ through a cuff placed on the middle phalanx of the third finger. Beat-to-beat time series of systolic blood pressure and pulse interval will be constructed from blood pressure recording data; their variances correspond to heart rate variability and blood pressure variability, respectively. In addition, spectral analysis, using an autoregressive model, will be applied to estimate the center frequency and power of each relevant oscillatory component [41]. The spectral bands for human beings are defined as: very low frequency, 0.0 to $0.04 \mathrm{~Hz}$; low frequency, 0.04 to $0.15 \mathrm{~Hz}$; and high frequency, 0.15 to $0.40 \mathrm{~Hz}$, as described elsewhere [41].

\section{Controlled ventilation}

Individuals will be placed in the supine position for measurement of respiratory rate, heart rate, $\mathrm{SpO}_{2}$ by pulse oximetry, and mean arterial pressure, which will be measured using an automated sphygmomanometer (Dinamap 1846 SX/P, Critikon, Tampa, FL, USA) once per minute during the test. The glucose and blood pressure, calf blood flow (which will be measured by venous occlusion plethysmography (Hokanson TL-400, Bellevue, WA, USA)) will be recorded continuously.

Inspiratory volume will be assessed using a pneumotachograph (Pneumotach3700 series, Hans Rudolph, Kansas City, MO, USA). The end-tidal carbon dioxide concentration will be measured by oxycapnography (Takaoka Oxicap, São Paulo, Brazil) and maintained at eupneic levels during both protocols via addition of $\mathrm{CO}_{2}$ to the inspiratory circuit. Participants will be instructed to maintain a breathing frequency of 15 breaths per min and a duty cycle $\left(T_{\mathrm{I}} / T_{\text {Tot }}\right)$ of 0.7 by listening to an audio signal with distinct inspiratory and expiratory tones, and visual feedback will be displayed. 


\section{Acute inspiratory muscle exercise}

This protocol was developed by Dempsey et al. [44] to reduce diaphragm blood flow and cause fatigue. During the protocol, individuals will breathe continuously through a two-way valve (Hans Rudolph, 2600 series, Shawnee, KS, USA) with low resistance (2 \% of PImax) connected to an inspiratory resistance obtained by a threshold inspiratory muscle trainer (DHDInspiratory Muscle Trainer, Chicago, IL) or, for higher inspiratory pressures (60\% of PImax), to a POWERbreathe ${ }^{\bullet}$ inspiratory muscle trainer (Southam, UK). Inspiratory pressure will be continuously recorded and displayed on a computer screen shared through a television, providing visual feedback; the 10-point Borg scale [45] will be used to access inspiratory effort at task failure. Inability to maintain breathing will be defined as a reduction of PImax to less than $80 \%$ of the prescribed value during three consecutive breaths [38]. For the placebo experiments conducted at $2 \%$ of PImax, measurements will cease at $10 \mathrm{~min}$. The sequence of experiments, induction of the inspiratory muscle metaboreflex (60\% of PImax), or allocation to the placebo experiment ( $2 \%$ of PImax), will be randomized, and experiments will be conducted 1 week apart.

In both protocols, baseline data will be collected during $10 \mathrm{~min}$ of spontaneous breathing. After this period, a controlled ventilation protocol will be initiated, and individuals instructed to maintain a breathing frequency of 15 breaths per min and a duty cycle $\left(T_{\mathrm{I}} / T_{\mathrm{Tot}}\right)$ of 0.7 by listening to an audio signal with distinct inspiratory and expiratory tones for $10 \mathrm{~min}$. Calf blood flow will be measured by venous occlusion plethysmography (Hokanson, TL-400, Bellevue, WA, USA) every $10 \mathrm{~s}$ in the non-dominant lower limb. Calf vascular conductance will be calculated as calf blood flow divided by mean arterial pressure [46]. Blood pressure will be monitored once a minute using an automated monitor (Dinamap, USA), and heart rate will be monitored continuously throughout the protocol.

\section{Ethics and data protection issues}

Participation will be voluntary, and all ethical principles of confidentiality and data protection will be followed. All subjects will have to sign a standardized informed consent form prior to participating in the study. All procedures will be explained to participants, and information about the aim, design, potential risks and benefits, and all relevant details of the study will be provided in the informed consent form. The data obtained by the study will be available to the participant and to any other authorized person, and may be used anonymously for academic scientific purposes. The study protocol was approved by the
Institutional Review Board of Hospital de Clínicas de Porto Alegre, Brazil (number 14-0194) and registered at ClinicalTrials.gov (NCT02292810).

\section{Safety assessment}

Data on all adverse events will be collected and included in medical reports, which will be forwarded to the health authorities. To ensure patient safety, if any adverse events occur at any time during the study, participants will be monitored for up to 4 weeks after study exit.

\section{Statistical analysis}

Data will be expressed as means and standard deviations or medians and interquartile ranges for nonparametric variables. Two-way analysis of variance (ANOVA) for repeated measures will be used to evaluate averages before and after acute inspiratory muscle exercise, comparing the placebo ( $2 \%$ of PImax) and intervention (60\% of PImax) loads. Pearson correlation coefficients will be used to evaluate the association between components of cardiovascular autonomic control and glucose levels. For nonparametric variables, Spearman correlation will be used. The statistical power will be $80 \%$ and differences will be considered significant for $P<0.05$. All analyses will be performed using SPSS Statistics for Windows, version 20.0 (IBM Corp., Armonk, NY, USA).

\section{Discussion}

Exercise programs have traditionally emphasized aerobic exercise, because of its well-known cardiovascular [47], metabolic [48], and autonomic benefits in type 2 diabetes [24, 49]. Resistance training also has favorable effects on muscle strength, abdominal fat, insulin sensitivity [22], and blood pressure [21]. Furthermore, combined exercise is also beneficial for metabolic parameters $[19,20]$ and glucose variability in subjects with type 2 diabetes [18]. However, as not all patients tolerate conventional exercise and some find it difficult to adhere to fitness programs, alternatives must be developed to enable these patients to obtain the benefits of physical exercise. Inspiratory muscle training is a novel exercise modality that has demonstrated impressive beneficial effects on inspiratory muscle strength and resistance $[29,50]$ and in reduction of glucose variability [30]. However, given the relatively small sample size of our preliminary study [30], we planned to examine this question in greater depth through a new study with a larger sample of patients with type 2 diabetes, seeking to confirm that a single bout of inspiratory muscle exercise may provide a benefit similar to that achieved with aerobic exercise on glucose levels and glucose variability. In brief, this study will be conducted to evaluate glucose levels, glucose variability, and 
cardiovascular autonomic responses at rest, during, and after a session of acute inspiratory muscle exercise performed under two resistance loads (low, $2 \%$ of PImax; high, $60 \%$ of PImax).

\section{Trial status}

The trial is currently in the recruitment phase. Each patient is scheduled to attend nine hospital visits, and the total data collection time will be 10 months.

\section{Abbreviations}

ANOVA: analysis of variance; CONSORT: Consolidated Standards of Reporting Trials; HbA1c: glycated hemoglobin; PImax: maximal inspiratory pressure; $\mathrm{SpO}_{2}$ : oxygen saturation; $\mathrm{VO}_{2}$ peak: peak oxygen uptake..

\section{Competing interests}

The authors declare that they have no competing interests.

\section{Authors' contributions}

ASOS coordinated the recruitment. She participated in the sequence alignment, and drafted the manuscript. APSC participated in the sequence alignment, will perform the statistical analysis and drafted this manuscript. KRC participated in the sequence alignment and will participate in data analysis procedures. She reviewed and approved this manuscript. BDS is the main investigator of the study. She participated in the coordination of all tasks, will participate in data analysis procedures, and reviewed and approved the manuscript. All authors read and approved the final manuscript.

\section{Authors' information}

ASOS is a PhD student in the Postgraduate Program of Cardiology, School of Medicine, Universidade Federal do Rio Grande do Sul, Porto Alegre, Brazil. APSC is a post-doctoral student in the Postgraduate Program of Endocrinology, School of Medicine, Universidade Federal do Rio Grande do Sul. She is a collaborator of the Faculty of Health Sciences, University of Sydney, Lidcombe, NSW, Australia.

KRC is a professor in the Department of Science and Technology, Science and Technology Institute, Universidade Federal de São Paulo, São José dos Campos, São Paulo, Brazil.

BDS works in the Endocrine Division, Hospital de Clínicas de Porto Alegre RS, Brazil, and is a professor in Postgraduate Program of Endocrinology, School of Medicine, Universidade Federal do Rio Grande do Sul, Porto Alegre, Brazil.

\section{Acknowledgements}

This work was supported by a grant from the Coordenação de Aperfeiçoamento de Pessoal de Nível Superior, Brazil. This study was supported by Fundo de Incentivo à Pesquisa do Hospital de Clínicas de Porto Alegre. BDS was the recipient of an educational scholarship from Conselho Nacional de Desenvolvimento Científico e Tecnológico.

\section{Author details}

${ }^{1}$ Exercise Pathophysiology Research Laboratory, Hospital de Clínicas de Porto Alegre, Porto Alegre, Rio Grande do Sul, Brazil. ${ }^{2}$ Faculty of Health Sciences, University of Sydney, Lidcombe, New South Wales, Australia. ${ }^{3}$ Institute of Science and Technology, Universidade Federal de São Paulo, São Paulo, Brazil. ${ }^{4}$ Graduate Program in Endocrinology, Universidade Federal do Rio Grande do Sul, Porto Alegre, Rio Grande do Sul, Brazil. 'Endocrine Division, Hospital de Clínicas de Porto Alegre, Porto Alegre, Rio Grande do Sul, Brazil.

Received: 26 June 2015 Accepted: 5 January 2016

Published online: 20 January 2016

\section{References}

1. Goldhaber-Fiebert JD, Goldhaber-Fiebert SN, Tristan ML, Nathan DM Randomized controlled community-based nutrition and exercise intervention improves glycemia and cardiovascular risk factors in type 2 diabetic patients in rural Costa Rica. Diabetes Care. 2003;26(1):24-9.
2. Colberg SR, Sigal RJ, Fernhall B, Regensteiner JG, Blissmer BJ, Rubin $\mathrm{RR}$, et al. Exercise and type 2 diabetes: the American College of Sports Medicine and the American Diabetes Association: joint position statement. Diabetes Care. 2010;33(12):e147-67. doi:10.2337/dc10-9990.

3. UK Prospective Diabetes Study (UKPDS) Group. Intensive blood-glucose control with sulphonylureas or insulin compared with conventional treatment and risk of complications in patients with type 2 diabetes (UKPDS 33). Lancet. 1998;352(9131):837-53.

4. The Diabetes Control and Complications Trial Research Group. The effect of intensive treatment of diabetes on the development and progression of long-term complications in insulin-dependent diabetes mellitus. N Engl J Med. 1993;329(14):977-86. doi:10.1056/ NEJM199309303291401.

5. Standards of medical care in diabetes - 2015: summary of revisions. Diabetes care. 2015; 38(Suppl):S4. doi:10.2337/dc15-S003.

6. Gaede $\mathrm{P}$, Lund-Andersen $\mathrm{H}$, Parving $\mathrm{HH}$, Pedersen $\mathrm{O}$. Effect of a multifactorial intervention on mortality in type 2 diabetes. N Engl J Med. 2008;358(6):580-91. doi:10.1056/NEJMoa0706245.

7. Wegner $M$, Neddermann D, Piorunska-Stolzmann M, Jagodzinski PP. Role of epigenetic mechanisms in the development of chronic complications of diabetes. Diabetes Res Clin Pract. 2014;105(2):164-75. doi:10.1016/j.diabres. 2014.03.019.

8. Fadini GP. A reappraisal of the role of circulating (progenitor) cells in the pathobiology of diabetic complications. Diabetologia. 2014;57(1):4-15. doi: 10.1007/s00125-013-3087-6.

9. Satya Krishna SV, Kota SK, Modi KD. Glycemic variability: clinical implications. Indian J Endocrinol Metab. 2013;17(4):611-9. doi:10.4103/2230-8210.113751.

10. Monnier L, Wojtusciszyn A, Colette C, Owens D. The contribution of glucose variability to asymptomatic hypoglycemia in persons with type 2 diabetes. Diabetes Technol Ther. 2011;13(8):813-8. doi:10.1089/dia.2011.0049.

11. Wolpert HA. The nuts and bolts of achieving end points with real-time continuous glucose monitoring. Diabetes Care. 2008;31((Suppl 2)):S146-9. doi:10.2337/dc08-s238

12. Blevins T. Value and utility of self-monitoring of blood glucose in noninsulin-treated patients with type 2 diabetes mellitus. Postgrad Med. 2013; 125(3):191-204. doi:10.3810/pgm.2013.05.2668.

13. Dailey G. Assessing glycemic control with self-monitoring of blood glucose and hemoglobin A(1c) measurements. Mayo Clin Proc. 2007;82(2):229-35. doi:10.4065/82.2.229

14. Monnier L, Colette C, Owens DR. Glycemic variability: the third component of the dysglycemia in diabetes. Is it important? How to measure it? J Diabetes Sci Technol. 2008;2(6):1094-100.

15. Borg R, Kuenen JC, Carstensen B, Zheng H, Nathan DM, Heine RJ, et al. $\mathrm{HbA}(1)(\mathrm{c})$ and mean blood glucose show stronger associations with cardiovascular disease risk factors than do postprandial glycaemia or glucose variability in persons with diabetes: the A1C-Derived Average Glucose (ADAG) study. Diabetologia. 2011;54(1):69-72. doi:10.1007/s00125010-1918-2.

16. Service FJ, Molnar GD, Rosevear JW, Ackerman E, Gatewood LC, Taylor WF. Mean amplitude of glycemic excursions, a measure of diabetic instability. Diabetes. 1970;19(9):644-55.

17. Molnar GD, Taylor WF, Ho MM. Day-to-day variation of continuously monitored glycaemia: a further measure of diabetic instability. Diabetologia. 1972;8(5):342-8

18. Figueira FR, Umpierre D, Casali KR, Tetelbom PS, Henn NT, Ribeiro JP, et al. Aerobic and combined exercise sessions reduce glucose variability in type 2 diabetes: crossover randomized trial. PLoS One. 2013;8(3):e57733. doi:10. 1371/journal.pone.0057733.

19. Umpierre D, Ribeiro PA, Kramer CK, Leitao CB, Zucatti AT, Azevedo MJ, et al. Physical activity advice only or structured exercise training and association with $\mathrm{HbA} 1 \mathrm{c}$ levels in type 2 diabetes: a systematic review and meta-analysis. JAMA. 2011;305(17):1790-9. doi:10.1001/jama.2011.576.

20. Umpierre D, Ribeiro PA, Schaan BD, Ribeiro JP. Volume of supervised exercise training impacts glycaemic control in patients with type 2 diabetes: a systematic review with meta-regression analysis. Diabetologia. 2013;56(2): 242-51. doi:10.1007/s00125-012-2774-z

21. Figueira FR, Umpierre D, Cureau FV, Zucatti AT, Dalzochio MB, Leitao CB, et al. Association between physical activity advice only or structured exercise training with blood pressure levels in patients with type 2 diabetes: a systematic review and meta-analysis. Sports Med. 2014;44(11):1557-72. doi: 10.1007/s40279-014-0226-2. 
22. Ibanez J, Izquierdo M, Arguelles I, Forga L, Larrion JL, Garcia-Unciti M, et al Twice-weekly progressive resistance training decreases abdominal fat and improves insulin sensitivity in older men with type 2 diabetes. Diabetes Care. 2005;28(3):662-7.

23. Balducci S, Zanuso S, Nicolucci A, Fernando F, Cavallo S, Cardelli P, et al. Anti-inflammatory effect of exercise training in subjects with type 2 diabetes and the metabolic syndrome is dependent on exercise modalities and independent of weight loss. Nutr Metab Cardiovasc Dis. 2010;20(8):60817. doi:10.1016/j.numecd.2009.04.015.

24. Pagkalos M, Koutlianos N, Kouidi E, Pagkalos E, Mandroukas K, Deligiannis A. Heart rate variability modifications following exercise training in type 2 diabetic patients with definite cardiac autonomic neuropathy. $\mathrm{Br} J$ Sports Med. 2008:42(1):47-54. doi:10.1136/bjsm.2007.035303.

25. Vinik Al, Erbas T. Diabetic autonomic neuropathy. Handb Clin Neurol. 2013; 117:279-94. doi:10.1016/B978-0-444-53491-0.00022-5.

26. Geddes EL, O'Brien K, Reid WD, Brooks D, Crowe J. Inspiratory muscle training in adults with chronic obstructive pulmonary disease: an update of a systematic review. Respir Med. 2008;102(12):1715-29. doi:10.1016/j.rmed.2008.07.005

27. Mello PR, Guerra GM, Borile S, Rondon MU, Alves MJ, Negrao CE, et al. Inspiratory muscle training reduces sympathetic nervous activity and improves inspiratory muscle weakness and quality of life in patients with chronic heart failure: a clinical trial. J Cardiopulm Rehabil Prev. 2012;32(5): 255-61. doi:10.1097/HCR.0b013e31825828da.

28. Jaenisch RB, Hentschke VS, Quagliotto E, Cavinato PR, Schmeing LA, Xavier $\mathrm{LL}$, et al. Respiratory muscle training improves hemodynamics, autonomic function, baroreceptor sensitivity, and respiratory mechanics in rats with heart failure. J Appl Physiol (1985). 2011;111(6):1664-70. doi:10.1152/ japplphysiol.01245.2010.

29. Correa AP, Ribeiro JP, Balzan FM, Mundstock L, Ferlin EL, Moraes RS. Inspiratory muscle training in type 2 diabetes with inspiratory muscle weakness. Med Sci Sports Exerc. 2011;43(7):1135-41. doi:10.1249/MSS. Ob013e31820a7c12.

30. Correa AP, Figueira FR, Umpierre D, Casali KR, Schaan BD. Inspiratory muscle loading: a new approach for lowering glucose levels and glucose variability in patients with Type 2 diabetes. Diabet Med. 2015; 32(9):1255-7. doi:10.1111/dme.12798.

31. Corrêa AP SB, Antunes CF, Figueira FR, Castro MA, Ribeiro JP., editor. Exacerbated inspiratory muscle metaboreflex in diabetic patients with autonomic neuropathy. In: $1^{\text {st }}$ American Diabetes Association Middle East Congress: Diabetes Prevention and Treatment, Dubai, UAE 2012. Diabetes Care. 2012; 9(Suppl 4):S14.

32. Schulz KF, Altman DG, Moher D. CONSORT 2010 statement: updated guidelines for reporting parallel group randomised trials. BMJ. 2010;340: c332. doi:10.1136/bmj.c332.

33. Severo MD, Leiria LF, Ledur Pdos S, Becker AD, Aguiar FM, Massierer D, et al. Association between erectile dysfunction and echocardiographic variables of ventricular hypertrophy and diastolic function in hypertensive patients with type 2 diabetes mellitus: a cross-sectional study. J Diabetes. 2014;6(6): 586-94. doi:10.1111/1753-0407.12133.

34. Ewing DJ, Martyn CN, Young RJ, Clarke BF. The value of cardiovascular autonomic function tests: 10 years experience in diabetes. Diabetes Care. 1985;8(5):491-8.

35. Neumann C, Schmid H. Standardization of a computerized method for calculating autonomic function test responses in healthy subjects and patients with diabetes mellitus. Braz J Med Biol Res. 1997;30(2):197-205.

36. Dall'Ago P, Chiappa GR, Guths H, Stein R, Ribeiro JP. Inspiratory muscle training in patients with heart failure and inspiratory muscle weakness: a randomized trial. J Am Coll Cardiol. 2006;47(4):757-63. doi:10.1016/j.jacc.2005.09.052.

37. Callegaro CC, Martinez D, Ribeiro PA, Brod M, Ribeiro JP. Augmented peripheral chemoreflex in patients with heart failure and inspiratory muscle weakness. Respir Physiol Neurobiol. 2010;171(1):31-5. doi:10.1016/j.resp.2010.01.009.

38. American Thoracic Society/European Respiratory Society. ATS/ERS statement on respiratory muscle testing. Am J Respir Crit Care Med. 2002;166(4):518-624. doi:10.1164/rccm.166.4.518.

39. Kovatchev BP, Otto E, Cox D, Gonder-Frederick L, Clarke W. Evaluation of a new measure of blood glucose variability in diabetes. Diabetes Care. 2006; 29(11):2433-8. doi:10.2337/dc06-1085.

40. Hill NR, Oliver NS, Choudhary P, Levy JC, Hindmarsh P, Matthews DR. Normal reference range for mean tissue glucose and glycemic variability derived from continuous glucose monitoring for subjects without diabetes in different ethnic groups. Diabetes Technol Ther. 2011;13(9):921-8. doi:10.1089/dia.2010.0247.

41. Malliani A, Pagani M, Lombardi F, Cerutti S. Cardiovascular neural regulation explored in the frequency domain. Circulation. 1991;84(2):482-92.

42. Porta A, Guzzetti S, Montano N, Furlan R, Pagani M, Malliani A, et al. Entropy, entropy rate, and pattern classification as tools to typify complexity in short heart period variability series. IEEE Trans Biomed Eng. 2001;48(11):1282-91. doi:10.1109/10.959324.

43. Sherwood A, Allen MT, Fahrenberg J, Kelsey RM, Lovallo WR, van Doornen LJ. Methodological guidelines for impedance cardiography. Psychophysiology. 1990;27(1):1-23.

44. Dempsey JA, Amann M, Romer LM, Miller JD. Respiratory system determinants of peripheral fatigue and endurance performance. Med Sci Sports Exerc. 2008;40(3):457-61. doi:10.1249/MSS.0b013e31815f8957.

45. Hamilton AL, Killian KJ, Summers E, Jones NL. Muscle strength, symptom intensity, and exercise capacity in patients with cardiorespiratory disorders. Am J Respir Crit Care Med. 1995;152(6 Pt 1):2021-31. doi:10.1164/ajrccm.152.6.8520771.

46. Roseguini BT, Alves CN, Chiappa GR, Stein R, Ribeiro JP. Muscle metaboreflex contribution to resting limb haemodynamic control is preserved in older subjects. Clin Physiol Funct Imaging. 2007;27(5):335-9. doi:10.1111/j.1475-097X.2007.00756.X.

47. Hu FB, Stampfer MJ, Solomon C, Liu S, Colditz GA, Speizer FE, et al. Physical activity and risk for cardiovascular events in diabetic women. Ann Intern Med. 2001:134(2):96-105.

48. Winnick JJ, Sherman WM, Habash DL, Stout MB, Failla ML, Belury MA, et al. Short-term aerobic exercise training in obese humans with type 2 diabetes mellitus improves whole-body insulin sensitivity through gains in peripheral, not hepatic insulin sensitivity. J Clin Endocrinol Metab. 2008;93(3):771-8. doi:10.1210/jc.2007-1524.

49. Howorka K, Pumprla J, Haber P, Koller-Strametz J, Mondrzyk J, Schabmann A. Effects of physical training on heart rate variability in diabetic patients with various degrees of cardiovascular autonomic neuropathy. Cardiovasc Res. 1997;34(1):206-14

50. Kaminski DM, Schaan BD, da Silva AM, Soares PP, Plentz RD, Dall'Ago P. Inspiratory muscle weakness is associated with autonomic cardiovascular dysfunction in patients with type 2 diabetes mellitus. Clin Auton Res. 2011; 21(1):29-35. doi:10.1007/s10286-010-0087-1.

\section{Submit your next manuscript to BioMed Central and we will help you at every step:}

- We accept pre-submission inquiries

- Our selector tool helps you to find the most relevant journal

- We provide round the clock customer support

- Convenient online submission

- Thorough peer review

- Inclusion in PubMed and all major indexing services

- Maximum visibility for your research

Submit your manuscript at www.biomedcentral.com/submit
C) Biomed Central 